\title{
PEMANFAATAN DIGITAL ENABLER DALAM TRANSFORMASI PEMASARAN DESA WISATA BERBASIS KERAKYATAN DI BALI
}

\author{
Bagus Putu Wahyu Nirmala ${ }^{1}$ Sephy Lavianto ${ }^{2)}$ \\ Program Studi Sistem Informasi ${ }^{1)}$ \\ Program Studi Sistem Informasi Akuntansi ${ }^{2)}$ \\ Sekolah Tinggi Manajemen Informatika dan Komputer (STMIK) Primakara, Denpasar, Bali ${ }^{1{ }^{2}{ }^{2}}$

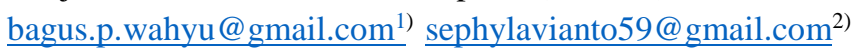

\begin{abstract}
Tourism Village is believed to be a solution for destination management that is pro-community (community based tourism). On the island of Bali, there is a policy that aims to accelerate the development of tourist villages, namely Surat Edaran Kadisparda Nomor 556/317/I/DISPAR concerning the Development of 100 Tourism Villages in 2014-2018. Villages that has long been developed into a tourist village in Bali is Penglipuran Village and Taro Village. One of threat in the digital era, there has been a digitalization of business processes, including in the field of tourism village marketing, so innovation is needed in order to transform the tourism village marketing by utilizing digital enablers. Devices that are classified as digital enablers are mobile devices / mobile applications, internet of things, social media, QR codes and so on.This study focuses on utilizing digital enablers in order to transform marketing in two tourist villages, namely Penglipuran Village and Taro Village in the form of an application. It is expected that applications that empower digital enabler technology can help achieve five marketing functions of Digital Marketing Framework. The object of this research is marketing tourism villages in Bali with digital enablers using applications and integrating devices classified as digital enablers.
\end{abstract}

Keywords: digital enabler, e-tourism, digital marketing framework, Bali village.

\begin{abstract}
ABSTRAK
Desa Wisata diyakini menjadi solusi manajemen destinasi yang pro-masyarakat lokal (community based tourism). Di pulau Bali, ada kebijakan yang bertujuan untuk mempercepat pengembangan desa wisata, yaitu Surat Edaran Kadisparda Nomor 556/317 / I / DISPAR tentang Pengembangan 100 Desa Wisata di 2014-2018. Desa yang telah lama dikembangkan menjadi desa wisata di Bali adalah Desa Penglipuran dan Desa Taro. Salah satu ancaman di era digital, telah terjadi digitalisasi proses bisnis, termasuk di bidang pemasaran desa wisata, sehingga diperlukan inovasi dalam untuk mengubah pemasaran desa wisata dengan memanfaatkan digital enabler. Perangkat yang diklasifikasikan sebagai digital enabler adalah perangkat seluler / aplikasi seluler, internet, media sosial, QRcode, dan sebagainya. Studi ini berfokus pada pemanfaatan digital enabler untuk mengubah pemasaran di dua desa wisata, yaitu Desa Penglipuran dan Desa Taro dalam bentuk aplikasi. Diharapkan bahwa aplikasi yang memberdayakan teknologi digital enabler dapat membantu mencapai lima fungsi Kerangka Pemasaran Digital. Objek penelitian ini adalah pemasaran desa wisata di Bali dengan digital enabler menggunakan aplikasi dengan mengintegrasikan beberapa perangkat.
\end{abstract}

Kata kunci: digital enabler, e-tourism, kerangka pemasaran digital, desa Bali. 


\section{PENDAHULUAN}

Konsep desa wisata menjadi isu hangat pada tahun 2000-an. Konsep desa wisata muncul ditengah kegagalan pembangunan pariwisata masal serta munculnya kesadaran yang lebih memberdayakan masyarakat lokal. Desa wisata dipercaya menjadi solusi pengelolaan destinasi wisata yang berpihak pada masyarakat atau lebih dikenal community based tourism atau pariwisata berbasis kerakyatan. Pariwisata berbasis kerakyatan dicirikan dengan keterlibatan masyarakat dalam proses perencanaan, penggunaan pengetahuan dan teknologi lokal, upaya meningkatkan kapasitas masyarakat lokal, dan serta usaha untuk mengurangi kebocoran ekonomi ${ }^{[9]}$.

Di Bali, lahirnya konsep desa wisata mendapat sambutan positif berbagai pihak dari masyarakat hingga pemerintah. Pemerintah melahirkan kebijakan yang mendukung percepatan pembangunan desa wisata. Dinas Pariwisata Provinsi Bali menerbitkan Surat Edaran Kadisparda Provinsi Bali Nomor 556/317/I/DISPAR tentang Pengembangan 100 Desa Wisata Tahun 2014-2018 di Bali. Menurut Kompas.com hingga tahun 2017 telah ada 67 desa yang sudah terbentuk dan dibina menjadi desa wisata. Desa wisata yang sudah lama berkembang seperti Desa Penglipuran di Kabupaten Bangli dan Desa Taro di Kabupaten Gianyar. Dua desa tersebut memiliki keunikan tersendiri. Desa Penglipuran yang terkenal dengan penataan arsitektur dan penataan rumah yang rapi. Desa Taro terkenal dengan adat istiadatnya dan keberadaan sapi putih yang disucikan. Dua desa ini merupakan desa wisata yang sudah lama berkembang dan memiliki kesiapan dalam menerima kunjungan wisatawan. Kesiapan yang dimaksud disini adalah fasilitas pariwisata serta masyarakatnya yang sudah memiliki keterampilan hospitality. Dengan demikian kedua desa wisata ini siap untuk dipasarkan sebagai desa wisata.

Pengembangan sebuah desa menjadi desa wisata harus melewati berbagai kendala dan tantangan baik pada tahap perencanaan, pembangunan fasilitas pariwisata, pengembangan sumber daya manusia hingga pemasarannya. Salah satu tantangan yang harus dihadapi pada tahapan pemasaran di era digital ini adalah adaptasi teknologi informasi dan komunikasi untuk pemasaran desa wisata. Nyoman Wardawan, Kabid. Pengembangan Destinasi Disparda Prov. Bali menyatakan bahwa masih kurangnya pemanfaatan teknologi dalam rangka digitalisasi oleh desa wisata ${ }^{[14]}$.

"Desa wisata memanfaatkan digitalisasi masih minim. Ini peran pihak terkait sangat dibutuhkan. pengembangan digitalisasi desa wisata membutuhkan sinergi semua pihak termasuk pemerintah, swasta, perbankan, praktisi, masyarakat dan instansi terkait lainnya."

Kutipan tersebut menunjukkan bahwa Pemerintah Provinsi Bali mengharapkan adanya sistem digital yang diterapkan pelaku usaha di desa wisata di Provinsi Bali. Sistem digital ini akan diterapkan baik dari sisi pemasaran dalam jaringan maupun mendukung transaksi keuangan.

Perkembangan teknologi informasi dan komunikasi di era digital ini telah membawa dunia pariwisata pada era baru yaitu etourism. Di era ini, terjadi proses digitalisasi proses bisnis, value chain dan informasi di bidang pariwisata ${ }^{[2]}$. Dalam hal pemasaran untuk desa wisata dibutuhkan langkah kreatif dan inovatif untuk memberdayakan teknologi informasi dan komunikasi dalam rangka mentransformasi pemasaran desa wisata atau disebut digital enabling. Berbagai teknologi yang dapat dimanfaatkan dalam rangka digital enabling adalah perangkat bergerak/aplikasi mobile, internet of things, social media, QR code dan sebagainya. Pemanfaatan teknologi informasi dan komunikasi dalam rangka pemasaran digital desa wisata harus memperhatikan bagaimana fungsi pemasaran digital dapat dicapai. Terdapat lima fungsi pemasaran digital yaitu attract, engage, retain, learn dan relate ${ }^{[6]}$. Jika teknologi digital enabler yang diterapkan di desa wisata bertujuan untuk pemasaran 
maka lima fungsi pemasaran digital harus dicapai.

Desa wisata sebagai bentuk realisasi dari pariwisata kerakyatan melibatkan komponen masyarakat dalam pengelolaannya. Terkait dengan transformasi pemasaran konvensional menjadi digital maka masyarakat desa membutuhkan sebuah sarana yang memungkinkan hal tersebut. Sarana ini berbentuk aplikasi yang menjembatani penyampaian informasi pemasaran secara digital. Adanya aplikasi yang memberdayakan teknologi digital enabler dalam rangka pemasaran desa wisata bertujuan akhir meningkatkan kunjungan wisatawan. Meningkatnya kunjungan ini dapat memberikan multiplier effect pada motivasi masyarakat lokal dan pemerintah daerah dalam mengembangan desa wisatanya. Selain itu, dengan pahamnya masyarakat lokal terhadap digital enabler diharapkan dapat mengurangi kebocoran ekonomi lokal. Karena pemanfaatan teknologi digital enabler tersebut memungkinkan pemasaran usaha-usaha pariwisata yang dimiliki masyarakat lokal. Digital enabler juga memungkinkan informasi tentang desa dikendalikan oleh masyarakat sehingga diharapkan nilai dan budaya lokal lebih banyak disampaikan ke wisatawan.

Penelitian ini berfokus pada pemanfaatan digital enabler dalam rangka mentransformasi pemasaran di tiga desa wisata yaitu Desa Penglipuran dan Desa Taro dalam bentuk sebuah aplikasi. Diharapkan aplikasi yang memberdayakan teknologi digital enabler tersebut dapat membantu tercapainya lima fungsi pemasaran digital yaitu attract, engage, retain, learn dan relate. Dengan demikian tujuan akhir dari pemasaran yaitu meningkatnya kunjungan wisatawan dan multiplier effect lainnya dapat tercapai..

\section{TINJAUAN PUSTAKA}

\section{Digital Enabler Technology}

Teknologi digital enabler adalah sebuah teknologi yang terbentuk dari kinerja sekumpulan perangkat teknologi informasi dan komputer dan memungkinkan sebagai jembatan yang mentransformasi aktivitas bisnis konvensional ke arah digital. Dalam penelitian ini teknologi yang dimanfaatkan sebagai digital enabler adalah perangkat bergerak/aplikasi mobile, internet of things, social media, dan QR code.

\section{Aplikasi Mobile}

Aplikasi mobile adalah perangkat lunak yang dirancang untuk bekerja di perangkat bergerak, seperti komputer tablet atau smartphone. Aplikasi mobile sering berfungsi untuk memberi layanan yang serupa dengan yang diakses melalui komputer desktop. Aplikasi juga dikenal dengan istilah lain yaitu apps. Aplikasi yang dikembangkan dalam penelitian ini menggunakan sistem informasi Android. Android adalah salah satu sistem operasi yang berbasis Linux yang dipergunakan untuk perangkat bergerak. Android terdiri dari beberapa layer, antara lain Application and widget, Application Framework, Library, Android Runtime, dan Kernel.

\section{Internet of Things}

Internet of Things (IoT) merupakan istilah yang baru banyak digunakan dalam dekade terakhir ini. Meskipun istilah Internet of Things pertama kali digunakan oleh seorang pelopor teknologi asal Inggris bernama Kevin Ashton pada tahun 1999 untuk mendeskripsikan sebuah sistem yang memungkinkan objek di dunia nyata dapat terkoneksi ke internet dengan memanfaatkan sensor $^{[16]}$. Objek dalam internet of things mampu mentransfer data melalui jaringan tanpa membutuhkan interaksi manusia. Saat ini implementasi internet of things yang paling banyak digunakan adalah untuk machine-to-machine (M2M).

Disisi permintaan yaitu wisatawan,. Terkait dengan penggunaannya dalam pemasaran desa wisata, perangkat bergerak wisatawan yang telah dilengkapi sensor dan sebagainya akan mengumpulkan data dan memproses informasi yang diterima serta menggunakan proses tersebut untuk 
berbagai kebutuhan atau kondisi wisatawan saat melakukan perjalanan disebuah destinasi. Hal ini tentu akan mempermudah wisatawan melakukan perjalanan. Disisi penawaran yaitu masyarakat dapat melakukan pemasaran desa dan usaha-usaha yang tercakup di dalamnya melalui aplikasi mobile.

\section{Media Sosial}

Media sosial dapat didefinisikan sebagai kumpulan sistem dan aplikasi berbasis internet yang memungkinkan penggunanya untuk membuat, membagikan dan bertukar content, data dan informasi dengan pengguna lainnya dalam jaringan dalam sebuah komunitas digital. Terdapat pengelompokan media sosial yaitu weblog (contoh: wordpress.com, blogspot.com); microblog (contoh: twitter.com); social network (contoh: facebook.com, plus.google.com); media sharing (contoh: youtube.com, slideshare.com); social bookmarking (contoh: reddit, dig); rating \& review (contoh: tripadvisor.com); forum (contoh: kaskus.co.id) dan virtual world (contoh: Second Life) ${ }^{[15]}$.

\section{QR Code}

QR Code adalah bentuk evolusi dari barcode atau kode batang. Jika barcode adalah kode 1 dimensi sedangkan QR code adalah kode 2 dimensi.QR sendiri merupakan singkatan dari quick response. Sesuai dengan namanya, maka QR code bertujuan untuk menyampaikan informasi secara cepat dan mendapatkan respon yang cepat pula. QR code berfungsi sebagai tautan dalam bentuk fisik yang dapat mampu menyimpan alamat dan URL, nomor telepon, teks dan sms dimana tautan fisik ini dapat diletakan pada berbagai media seperti media cetak, marka-marka diruang publik, kartu nama dan sebagainya.

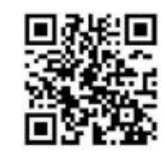

Gambar 1. Contoh Gambar QR code

\section{E-Tourism}

Kemajuan teknologi informasi dan komunikasi telah menyentuh dunia pariwisata. Perkembangan teknologi di era digital ini telah membawa dunia pariwisata pada era baru yaitu e-tourism. Buhalis dan Jun menyatakan "e-Tourism reflects the digitisation of all processes and value chains in the tourism, travel, hospitality and catering industries" "[2].

E-tourism dapat dipahami sebagai digitalisasi semua proses dan rantai nilai dalam industri pariwisata guna meningkatkan efektivitas dan efisiensi proses itu sendiri ${ }^{[11]}$. E-tourism bisa melibatkan berbagai fungsi bisnis dalam industri pariwisata sehingga kegiatannya meliputi e-commerce, e-marketing, $e$ finance, e-accounting, e-HRM, eprocurement, e-R\&D dan e-production ${ }^{[2]}$. Terkait dengan penelitian ini e-tourism berfokus pada pemasaran desa wisata dengan memanfaatkan teknologi digital enabler. Digital enabler yang memanfaatkan perangkat bergerak/aplikasi mobile, internet of things, social media, QR code memberikan keuntungan bagi dunia pariwisata dalam hal ini desa wisata. Teknologi informasi dan komunikasi saat ini memungkinkan pengelola desa wisata melakukan interaksi dan komunikasi secara digital dengan wisatawan dengan memanfaatkan media seperti aplikasi mobile.

\section{Kerangka Pemasaran Digital}

Keberhasilan pemasaran sebuah desa wisata dipengaruhi efektivitas pemanfaatan digital enabler yang dikembangkan. Untuk dapat berfungsi sebagai pemasaran, alat pemasaran harus mampu mencapai fungsifungsi pemasaran digital. Tidak semua alat pemasaran dapat mencapai semua fungsi pemasaran digital. Ada yang sangat baik digunakan untuk menarik (attract) pengunjung, berhubungan (relate) atau untuk memperoleh keterlibatan (engage) pengunjung. Sebuah kerangka pemasaran digital (digital marketing framework) telah dikembangkan oleh Kierzkowski ${ }^{[6]}$. 
Kerangka pemasaran digital menunjukkan fungsi-fungsi pemasaran digital yaitu attract, engage, retain, learn dan relate.

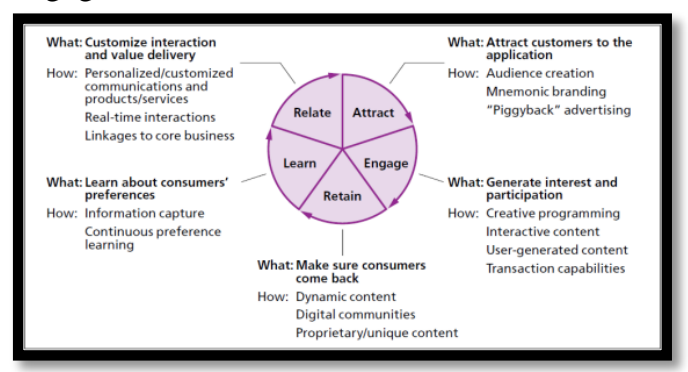

Gambar 2. Kerangka Pemasaran Digital ${ }^{[6]}$

\section{Desa Wisata}

Desa wisata adalah salah satu bentuk pariwisata yang menerapkan konsep pariwisata berbasis kerakyatan. Menurut Diarta, Sarjana, dan Wijayanti (2009) desa wisata adalah bentuk wisata dengan lingkungan pedesaan sebagai produk utama yang meliputi kegiatan atau kebiasaan hidup sehari-hari dalam komunitas lokal yang memiliki identitas tersendiri, bersifat kedekatannya dengan alam, serta dengan penduduk dari wilayah pedesaan yang dituju. Menurut penerapan desa wisata banyak melibatkan wisatawan dalam kehidupan masyarakat lokal sehingga wisatawan dapat mempelajari adat istiadat setempat, gaya hidup masyarakat, dan nilainilai komunitas local ${ }^{[10]}$. Kedua desa dalam penelitian ini yaitu Desa Penglipuran dan Desa Taro memberdayakan masyarakat adat dalam pengelolaannya. Terkait penelitian ini dibutuhkan pemahaman/pengetahuan sehingga masyarakat dapat memasarkan desanya secara digital.

\section{METODOLOGI PENELITIAN}

\section{Metode Penelitian}

Metode penelitian yang digunakan dalam penelitian ini adalah metode penelitian dan pengembangan (research and development). Metode penelitian dan pengembangan digunakan untuk mengembangkan dan menguji produk tertentu. Penelitian dilakukan melalui dua tahap, tahap pertama dengan metode kualitatif sehinggga dapat diperoleh rancangan produk dan penelitian tahap ke dua dengan metode kuantitatif digunakan untuk menguji efektivitas produk tersebut.

Penelitian ini akan dilakukan selama 8 (delapan) bulan, mulai pada April 2018 sampai November 2018. Penelitian akan dilakukan di STMIK Primakara Jl. Tukad Badung No. 135 Denpasar, Bali, Desa Penglipuran dan Desa Taro.

\section{Alur Penelitian}

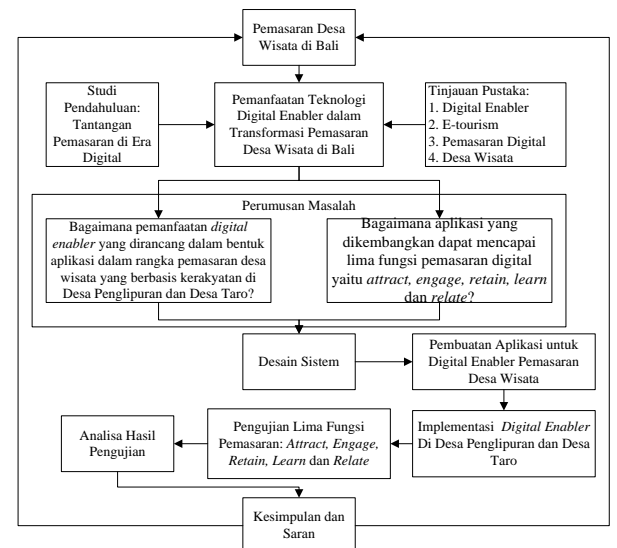

Gambar 3. Alur Penelitian

\section{Studi Pendahuluan}

Studi pendahuluan bertujuan untuk mendapatkan informasi dan data di lapangan terkait dengan pemasaran Desa Wisata konvensional (yang sudah berjalan) dan tantangan ke depan dalam pengelolaan Desa Wisata khususnya dalam pemasaran di era digital. Selain itu juga dilakukan studi terhadap teknologi digital enabler yang dalam penelitian ini diharapkan dapat membantu dalam menjawab tantangan pemasaran di era digital.

\section{Tinjauan Pustaka}

Tinjauan pustaka bertujuan untuk mendapatkan informasi tentang hal-hal yang sudah dilakukan oleh para peneliti sebelumnya, konsep dan teori terkait penelitian. Tinjauan pustaka dilakukan terhadap topik-topik terkait penelitian yaitu penelitian digital enabler, e-tourism, kerangka pemasaran digital dan Desa Wisata berbasis kerakyatan. 


\section{Perumusan Masalah}

Setelah studi pendahuluan dan tinjauan pustaka dilakukan, langkah selanjutnya adalah merumuskan masalah-masalah. Dalam penelitian ini telah ditentukan dua permasalahan yaitu (a) bagaimana pemanfaatan digital enabler yang dirancang dalam bentuk aplikasi dan (b) bagaimana aplikasi yang dikembangkan dapat mencapai lima fungsi pemasaran digital yaitu attract, engage, retain, learn dan relate.

\section{Desain Sistem}

Desain sistem dilakukan berdasarkan masalah yang telah diidentifikasi. Pada tahap ini akan dirancang sistem dari pemasaran desa wisata. Sistem yang dirancang dibuat agar dapat mengakomodasi fungsi pemasaran digital. Selanjutnya sistem yang dirancang akan diterjemahkan ke dalam kode program dan dalam tahap pembuatan aplikasi.

\section{Pembuatan Aplikasi}

Tahap ini bertujuan untuk menerjemahkan desain sistem ke dalam kode-kode program sehingga menghasilkan aplikasi untuk digital enabler pemasaran desa wisata. Aplikasi yang dibangun adalah aplikasi yang mampu memberdayakan teknologi digital enabler dalam rangka pemasaran desa wisata.

\section{Implementasi}

Setelah pembuatan aplikasi selanjutnya dilakukan proses implementasi. Implementasi akan dilakukan dengan memasang aplikasi ke smartphone Android.

\section{Pengujian Aplikasi Digital Enabler}

Pengujian bertujuan untuk mengetahui apakah aplikasi yang dibuat mampu mencapai lima fungsi pemasaran digital yaitu attract, engage, retain, learn dan relate. Tahap ini dilakukan dengan cara menyebarkan kuesioner.

\section{Analisis Hasil Penyebaran Kuesioner}

Analisis hasil penyebaran kuesioner bertujuan untuk mengetahui bagaimana hasil penerapan aplikasi dan mengukur kinerja aplikasi, apakah aplikasi yang dibuat berfungsi dengan baik atau tidak, apakah mampu mengakomodasi fungsi pemasaran digital.

\section{PERANCANGAN SISTEM}

\section{Arsitektur Sistem}

Aplikasi pemanfaatan teknologi digital enabler dalam bentuk aplikasi dapat dimanfaatkan oleh beberapa entitas seperti pada Gambar 7. Entitas yang dapat mengakses aplikasi ini adalah wisatawan, admin, dan pengelola wisata setempat. Wisatawan dapat melakukan scan terhadap QR Code yang tersebar di desa wisata, mengakses informasi berdasarkan hasil scan QR Code dan share informasi tersebut ke media sosial milik wisatawan. Pengelola wisata dapat menambahkan QR Code, informasi wisata yang berhubungan dengan QR Code yang baru di-submit serta mengkoneksikan informasi tersebut dengan beberapa saluran sosial media. Sedangkan admin bertugas pada pemeliharaan aplikasi seperti pembaharuan data informasi wisata.

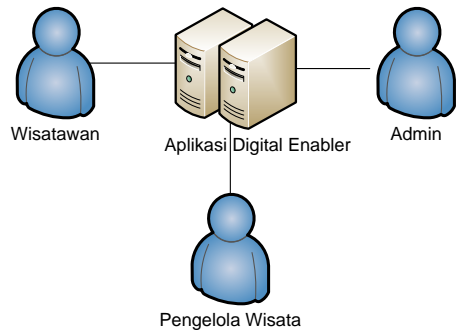

Gambar 4. Entitas Pengguna Sistem

\section{Desain Sistem}

Untuk mengakomodasi kebutuhan 3 entitas pengguna aplikasi ini beberapa fungsi yang dikembangkan untuk dimiliki oleh aplikasi ini adalah sebagai berikut :

- Untuk wisatawan fungsi yang disediakan Pilihan Desa Wisata, Data singkat Desa Wisata, Scan QR Code, Social Media Sharing,

- Untuk pengelola wisata fungsi yang disediakan adalah Request QR Code, Menambahkan informasi atraksi. 
- Untuk admin fungsi yang disediakan adalah Mengelola Data Desa Wisata, dan Mengelola Permintaan QR Code.

\section{Desain Interface}

Perancangan desain interface bertujuan untuk mendapatkan tampilan yang sesuai dengan kebutuhan penguna aplikasi dalam hal ini adalah wisatawan, admin, dan pengelola wisata. Interface yang baik adalah interface yang mampu mengakomodasi semua fungsi aplikasi tanpa mengurangi nilai estetika kenyamanan pengguna. Interface aplikasi pemanfaatan digital enabler untuk Desa Wisata Penglipuran dan Desa Wisata Taro adalah sebagai berikut.
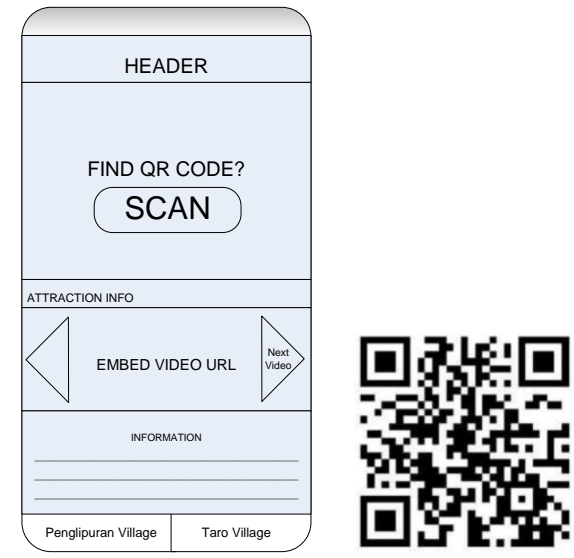

Gambar 5. Desain Interface Home \& QR

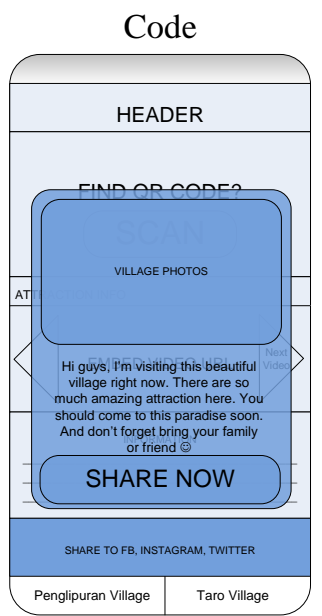

Gambar 6. Desain Interface Setelah Dilakukan Scan QRCode.

\section{HASIL DAN PEMBAHASAN}

\section{Aplikasi Digital Enabler}

Aplikasi pemanfaatan digital enabler dibuat berbasis android. Aplikasi yang sudah dirancang dan telah dibuatkan mock-up-nya. Berikut adalah desain antarmuka mockup aplikasi yang dikembangkan. Desain antarmuka memiliki peran yang penting sedemikian rupa sehingga aplikasi digital enabler dapat digunakan secara efisien dan efektif tanpa mengurangi kenyamanan pengguna.

\section{Efektivitas Aplikasi dan 5 Fungsi Pemasaran Digital}

Efektivitas sebuah aplikasi pemanfaatan digital enabler berhubungan erat dengan 5 fungsi pemasaran yang ditampilkan pada gambar 3.Dalam penelitian ini untuk mengetahui efektivitas aplikasi telah dikembangkan beberapa pertanyaan / pernyataan berdasarkan Kerangka Pemasaran Digital. Pernyataan / pertanyaan ini akan menjadi indikator yang digunakan dalam kuesioner yang menggunakan skala likert. Kemudian penyebaran kuesioner dilakukan di dua desa yaitu Desa Wisata Penglipuran dan Desa Wisata Taro diperoleh hasil rekapitulasi sebagai berikut :

Tabel 1. Rekapitulasi Hasil Penyebaran Kuesioner

\begin{tabular}{|l|l|c|}
\hline Var. & \multicolumn{1}{|c|}{ Pernyataan } & Nilai \\
\hline X1.1 & $\begin{array}{l}\text { QR code scanner (fitur } \\
\text { scan QR Code untuk } \\
\text { memunculkan portal/situs } \\
\text { resmi Desa Wisata.) }\end{array}$ & 4,13 \\
\hline X1.2 & $\begin{array}{l}\text { Penyediaan QRCode di } \\
\text { lokasi-lokasi strategis } \\
\text { sekitar Desa Wisata. }\end{array}$ & 4,3 \\
\hline X1.3 & $\begin{array}{l}\text { Mendaftarkan aplikasi di } \\
\text { google playstore agar } \\
\text { mudah diunduh oleh } \\
\text { wisatawan }\end{array}$ & 4,33 \\
\hline X1 & Attracting & $\mathbf{4 , 2 5}$ \\
\hline Xontent di media online \\
X2.1 & $\begin{array}{l}\text { yang informatif, unik dan } \\
\text { berguna bagi wisatawan } \\
\text { selama mengunjungi Desa } \\
\text { Wisata. }\end{array}$ & $\begin{array}{l}\text { Fitur } \text { social share yang } \\
\text { mampu sharing di media } \\
\text { sosialnya dan membantu } \\
\text { pemasaran desa wisata }\end{array}$ \\
\hline
\end{tabular}




\begin{tabular}{|c|c|c|}
\hline & $\begin{array}{l}\text { sehingga desa wisata lebih } \\
\text { dikenal oleh rekan-rekan } \\
\text { anda. }\end{array}$ & \\
\hline $\mathrm{X} 2.3$ & $\begin{array}{l}\text { Fitur peta lokasi desa } \\
\text { wisata sehingga } \\
\text { mengetahui letak geografis } \\
\text { dan daya tarik sekitar desa } \\
\text { wisata. }\end{array}$ & 3,8 \\
\hline $\mathrm{X} 2$ & Engaging & 4,13 \\
\hline X3.1 & $\begin{array}{l}\text { Melakukan update content } \\
\text { event budaya di desa } \\
\text { secara berkala agar } \\
\text { informasi di aplikasi } \\
\text { terlihat fresh. }\end{array}$ & 4,35 \\
\hline X3.2 & $\begin{array}{l}\text { Memperbanyak informasi- } \\
\text { informasi terkait desa } \\
\text { wisata seperti sejarah desa } \\
\text { wisata, foto-foto/video } \\
\text { tentang desa wisata. }\end{array}$ & 3,73 \\
\hline X3.3 & $\begin{array}{l}\text { Membuat aplikasi yang } \\
\text { ringan sehingga loading } \\
\text { time menjadi lebih cepat. }\end{array}$ & 4,06 \\
\hline X3 & Retaining & 4,05 \\
\hline $\mathrm{X} 4.1$ & $\begin{array}{l}\text { Memanfaatkan cookies } \\
\text { untuk identifikasi repeat } \\
\text { wisatawan atau IP address. }\end{array}$ & 4,02 \\
\hline $\mathrm{X} 4.2$ & $\begin{array}{l}\text { Memanfaatkan apps page } \\
\text { tracking feature untuk } \\
\text { mengetahui media online } \\
\text { yang digunakan oleh } \\
\text { wisatawan. }\end{array}$ & 4,12 \\
\hline $\mathrm{X} 4$ & Learning & 4.1 \\
\hline X5.1 & $\begin{array}{l}\text { Mengirimkan promosi / } \\
\text { newsletter / update kepada } \\
\text { wisatawan. }\end{array}$ & 4,06 \\
\hline $\mathrm{X5}$ & Relating & 4,06 \\
\hline
\end{tabular}

Dari hasil kuesioner di atas dapat diketahui bahwa aplikasi digital enabler yang dirancang dinilai dapat memberikan fungsi menarik (attract) minat wisatawan untuk mengetahui lebih dalam mengenai desa wisata yang dikunjungi seperti Desa Wisata Penglipuran dan Desa Taro dengan nilai 4.25. Fungsi ini dicapai melalui tiga indikator yaitu X1.1 QR code scanner dengan nilai 4,13; X1.2 Penyediaan QRCode di lokasi-lokasi strategis dengan nilai 4,3 ;
X1.3 Mendaftarkan aplikasi di google playstore dengan nilai 4,33.

Sedangkan untuk fungsi keterlibatan (engaging) atau keikutsertaan, aplikasi digital enablar dinilai positif dalam mencapai fungsi tersebut yaitu 4.13. Fungsi ini dicapai melalui tiga indikator yaitu X2.1 Content yang informatif, unik dan berguna bagi wisatawan dengan nilai 4,29; X2.2 Fitur social share yang dapat membantu pemasaran desa wisata dengan nilai 4,3 ; X2.3 Fitur peta lokasi desa wisata sehingga mengetahui daya tarik sekitar dengan nilai 3,8. Indikator X2.3 dinilai paling rendah dari fungsi engaging.

Fungsi mempertahankan (retaining) waktu kunjungan wisatawan selama berkunjung di desa wisata dapat dicapai dengan menerapkan aplikasi digital enabler. Dari hasil kuesioner diperoleh nilai 4.05 dimana berarti wisatawan setuju bahwa aplikasi yang dirancang dapat mempertahankan waktu kunjungan melalui tiga indikator yaitu X3.1 Melakukan update content event budaya secara berkala dengan nilai 4,35; X3.2 Memperbanyak informasi terkait desa wisata dengan nilai 3,73 ; X3.3 Membuat aplikasi yang ringan dengan nilai 4,06 . Indikator perbanyak informasi terkait desa wisata memiliki nilai yang paling rendah. Hal ini dapat diantisipasi dengan merubah format informasi dari bentuk text ke audio visual agar lebih menarik.

Fungsi mempelajari (learning) wisatawan yang berkunjung mendapatkan nilai 4.1. Fungsi ini dicapai dengan dua indikator yaitu X4.1 Memanfaatkan cookies untuk identifikasi IP address dengan nilai 4,02 ; X4.2 Memanfaatkan apps page tracking feature untuk mengetahui media online yang digunakan oleh wisatawan dengan nilai 4,12. Sedangkan fungsi membangun hubungan (relating) antara pengelola dengan wisatawan dapat dicapai oleh aplikasi digital enabler dengan nilai 4.06 melalui indikator mengirimkan promosi / newsletter / update kepada wisatawan.

Dengan dicapainya 5 fungsi pemasaran digital ini, diharapkan masyarakat lokal lebih memotivasi wisatawan dalam 
menggunakan aplikasi digital enabler. Alihalih wisatawan untuk lebih "eksis" di media sosial melalui fitur social share yaitu SHARE NOW. Dengan demikian wisatawan juga dapat membantu pemasaran desa wisata yang dikunjungi berdasarkan pada keaktifan masyarakat mempromosikan aplikasi digital enabler ini.

\section{SIMPULAN}

Aplikasi yang memanfaatkan teknologi digital enabler dalam rangka pemasaran desa wisata berbasis kerakyatan di Desa Penglipuran dan Desa Taro yang telah berhasil dirancang melalui beberapa tahapan pengembangan sehingga mampu menghadirkan fungsi pemasaran digital bagi Desa Taro dan Desa Penglipuran. Aplikasi yang dikembangkan juga mampu mencapai 5 fungsi pemasaran berdasarkan kerangka pemasaran digital yaitu fungsi attracting (dengan nilai $\mathrm{X} 1=4.25$ ), fungsi engaging (dengan nilai $\mathrm{X} 1=4.13$ ), fungsi retaining (dengan nilai $\mathrm{X} 1=4.05$ ), fungsi learning (dengan nilai $\mathrm{X} 1=4.1$ ), dan fungsi relating (dengan nilai $\mathrm{X} 1=4.06$ ). Dengan dicapainya 5 fungsi pemasaran digital ini, diharapkan masyarakat lokal lebih memotivasi wisatawan dalam menggunakan aplikasi digital enabler. Alih-alih wisatawan untuk lebih "eksis" di media sosial melalui fitur social share yaitu SHARE NOW. Dengan demikian wisatawan juga dapat membantu pemasaran desa wisata yang dikunjungi berdasarkan pada keaktifan masyarakat mempromosikan aplikasi digital enabler ini.

\section{DAFTAR PUSTAKA}

[1] Andrade,S.C., Mason, H., 2009. Digital Imaging Trek: A Practical Model for Managing the Demand of the Digitally Enabled Traveller. Hershey: IDEA GROUP PUBLISHING

[2] Buhalis, D. \& Jun, S.H., 2011. ETourism. Contemporary Tourism Reviews, pp.1-38. Available at: http://www.goodfellowpublishers.com /free_files/Contemporary-TourismReview-Etourism66769a7ed0935d0765318203b843a64 d.pdf.

[3] Hays, S., Page, S.J., Buhalis, D.. 2012. Social media as a destination marketing tool: its use by national tourism organisations.Sumber: http://dx.doi.org/10.1080/13683500.20 12.662215. Diakses pada 18 Juni 2017.

[5] Kaur K. \& Kaur R.. 2016. Internet of Things to Promote Tourism: An Insight into Smart Tourism. Sumber: http://www.ijrter.com/papers/volume2/issue-4/internet-of-things-topromote-tourism-an-insight-intosmart-tourism.pdf. Diakses pada 1 Juli 2017.

[6] Kierzkowski A., McQuade S., Waitman R., dan Zeisser M.. Marketing To The Digital Consumer. The McKinsey Quarterly1996 No. 3. 1996. McKinsey \& Company p.5-21.

[7] Kompas. 2016. Bali Bangun 100 Desa Wisata. Sumber: http://travel.kompas.com/read/2016/06 /09/223400527/Bali.Bangun.100.Desa. Wisata. Diakses pada 16 Juni 2017.

[8] Leung, D., Law, R., Hoof, H.V., Buhalis, D.. 2013. Social Media in Tourism and Hospitality: A Literature Review. Sumber: https://www.academia.edu/2967096/D aniel_Leung_Rob_Law_Hubert_van_ Hoof_and_Dimitrios_Buhalis_2013_S ocial_Media_in_Tourism_and_Hospit ality_A_Literature_Review_Journal_o f_Travel_and_Tourism_Marketing_30 _1-2_3-22. Diakses oada 18 Juni 2017.

[9] Mandke, P. and Jamieson, W. (2001). Guiding Principles In Managing CommunityBased Tourism. Makalah dipresentasikan pada Proceeding National Seminar On Sustainable Tourism Development 2001. Bandung.

[10] Nirmala, B. P. W.. 2010. Perancangan Kebijakan Pengembangan Wisata Pedesaan Di Desa Jatiluwih Dengan Menggunakan Metode Dinamika Sistem. Bandung: Program Studi Teknik Industri Fakultas Teknologi Industri Institut Teknologi Bandung.

[11] Nirmala, B. P. W.. 2016. Persepsi Pengelola Hotel Bintang 1-5 Terhadap Media Online Sebagai Alat Pemasaran 
157 Jurnal Teknologi Informasi dan Komputer,Volume 5, Nomor 1, Januari 2019

Di Kecamatan Kuta, Kabupaten Badung, Provinsi Bali. Denpasar: Program Studi Magister Kajian Pariwisata Program Pascasarjana Universitas Udayana.

[12] Surat Edaran Kadisparda Provinsi Bali Nomor 556/317/I/DISPAR tentang Pengembangan 100 Desa Wisata 2014-2018 di Bali.

[13] Teo, T.S.H., dan Tan, J.S.. 2002. Senior Executives' Perceptions Of BusinessTo-Consumer (B2C) Online Marketing Strategies: The Case Of Singapore.Singapura: National University of Singapore.

[14] Wiguna, Dewa. 2017. Bali Harapkan Digitalisasi Pelaku Usaha Desa Wisata. Sumber http://www.antarabali.com/berita/1056 04/bali-harapkan-digitalisasi-pelakuusaha-desa-wisata. Diakses pada 17 Juni 2017.

[15] Zarrella, Dan. 2010. The Social Media Marketing Book. Canada: O'Reilly.

[16] _ 2015. The Internet of Things: An Overview Understanding The Issues and Challenges of a More Connected World. Geneva: Internet Society

[17] https://id.wikipedia.org/wiki/PHP

[18] https://id.wikipedia.org/wiki/MySQL 